\title{
Perivascular epithelioid cell tumor of the rectum: report of a case and review of the literature
}

\author{
Amane Kanazawa ${ }^{1 *}$, Shoichi Fujii ${ }^{1}$, Ten-i Godai ${ }^{1}$, Atsushi Ishibe ${ }^{1}$, Takashi Oshima', Tadao Fukushima', \\ Mitsuyoshi Ota', Norio Yukawa², Yasushi Rino ${ }^{2}$, Toshio Imada², Junko Ito ${ }^{3}$, Akinori Nozawa ${ }^{3}$, \\ Munetaka Masuda ${ }^{2}$ and Chikara Kunisaki ${ }^{1}$
}

\begin{abstract}
We report a case of perivascular epithelioid cell tumor arising in the rectum of a 55 -year-old woman. The tumor was treated by transanal endoscopic microsurgery. After 1 year follow-up, the patient is alive with no radiologic or endoscopic evidence of recurrence. Perivascular epithelioid cell tumor is a rare mesenchymal tumor characterized by co-expression of melanocytic and smooth muscle markers. This rare tumor can arise in various organs, including the falciform ligament, uterus, uterine cervix, liver, kidney, lung, breast, cardiac septum, pancreas, prostate, thigh, and gastrointestinal tract. Perivascular epithelioid cell tumor of the gastrointestinal tract is very rare, with only 23 previously reported cases. We review the literature on perivascular epithelioid cell tumors arising in the gastrointestinal tract.
\end{abstract}

Keywords: Perivascular epithelioid cell tumor, PEComa, Transanal endoscopic microsurgery

\section{Background}

Perivascular epithelioid cell tumors (PEComas) were defined as "mesenchymal tumours composed of histologically and immunohistochemically distinctive perivascular epithelioid cells" by the World Health Organization [1]. PEComas classically include a wide spectrum of entities, such as angiomyolipoma (AML), lymphangioleiomyomatosis (LAM), and clear-cell "sugar" tumors (CCST) of the lung. PEComas other than AML, LAM, and CCST are very rare mesenchymal tumors that have been referred to as PEComa-not otherwise specified (PEComa-NOS) [1,2]. A review of 51 cases of PEComa-NOS revealed that $41 \%$ of reported cases of PEComa-NOS originated in the uterine corpus [3].

Gastrointestinal PEComa-NOS are very rare. To our knowledge, 23 cases have been reported in the literature [4-22]; consequently, the clinical and biological characteristics of PEComa-NOS are poorly understood. We report a case of PEComa arising in the rectum and review the clinicopathological characteristics of gastrointestinal PEComa-NOS.

\footnotetext{
* Correspondence: amanex2009@gmail.com

'Gastroenterological Center, Yokohama City University Medical Center, 4-57 Urafune-cho Minami-ku, Yokohama-shi, Kanagawa-ken 232-0024, Japan Full list of author information is available at the end of the article
}

\section{Case presentation}

A 55-year-old woman was referred to our hospital because of a rectal submucosal tumor detected on a colonoscopic examination. She had undergone a sigmoidectomy for sigmoid colon carcinoma 2 years previously in our hospital. Postoperatively, the final disease stage was T1N0M0 (Stage I) according to the TNM classification. The histological subtype of the sigmoid colon cancer was moderately differentiated adenocarcinoma. There had been no evidence of recurrence or metastasis during 2 years follow-up. The patient showed no signs of tuberous sclerosis complex.

On digital rectal examination, a hard mass was palpated on the posterior wall of the rectum. The results of other physical examinations of the abdomen and other organs were normal. Laboratory data showed no marked abnormalities, including tumor markers such as carcinoembryonic antigen and carbohydrate antigen 19-9. Colonoscopic examination in our hospital revealed a submucosal tumor $3 \mathrm{~cm}$ in diameter arising in the posterior rectal wall, $10 \mathrm{~cm}$ from the anal verge (Figure 1a). The submucosal tumor was accompanied by an ulcer and superficial mucosal bleeding at its center. A biopsy was performed, but a histopathological diagnosis could not be established. An endoanal ultrasound scan showed

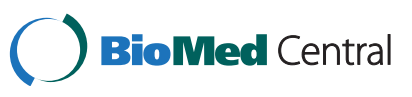



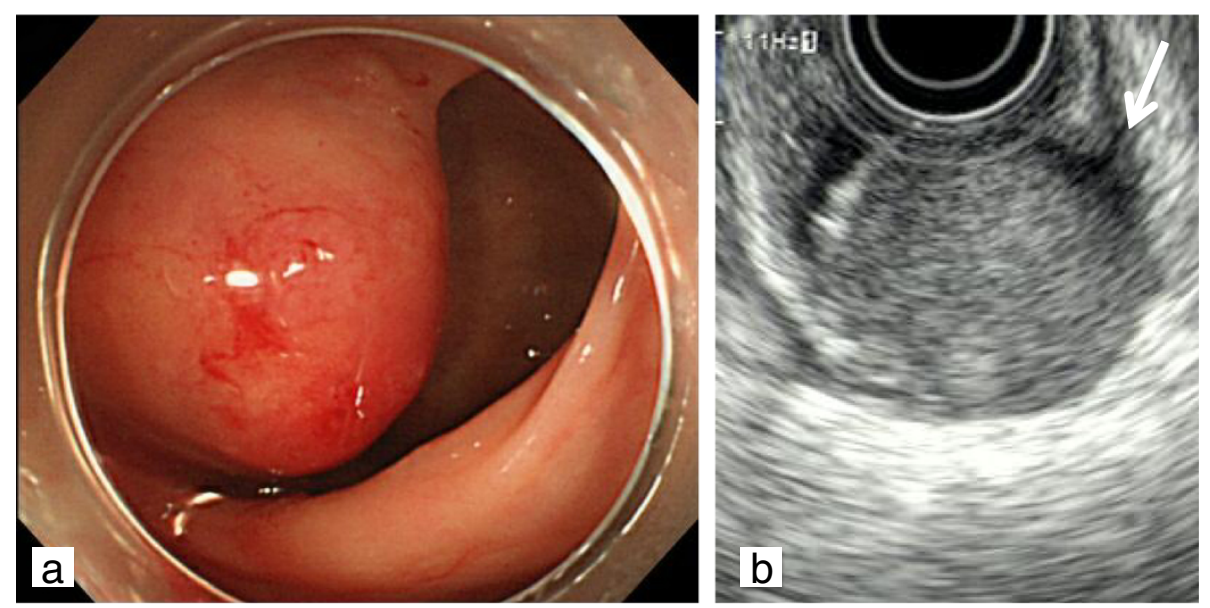

Figure 1 Findings on colonoscopy and endoanal ultrasound scanning. (a) Colonoscopic examination showed a submucosal tumor $3 \mathrm{~cm}$ in diameter arising in the posterior rectal wall. (b) Endoanal ultrasound scanning showed a heterogeneous, low-echoic tumor with a nodular appearance arising in the muscularis (long arrow) of the posterior rectal wall.

a heterogenous, low echoic, nodular tumor arising in the muscularis of the posterior rectal wall (Figure 1b). The tumor was suspected to invade the muscularis propria and subserosa. Contrast-enhanced computed tomography of the chest, abdomen, and pelvis detected no lymph node lesions around the rectum or metastasis to other organs.

The patient underwent transanal endoscopic microsurgery for a suspected diagnosis of rectal stromal tumor. We excised the full-thickness of the rectal wall excision with a $1 \mathrm{~cm}$ safety margin of normal mucosa around the tumor. The wound in the rectal wall was closed with a running suture. Macroscopically, the resected specimen showed a brown mass $2.5 \mathrm{~cm}$ in maximum diameter, with a central ulcer, an ill-defined border, and no capsule formation. Surface ulceration was prominent in association with absence of the rectal mucosa, which was ascribed to a prior endoscopic biopsy.

On microscopic examination, the tumor resided mainly in the musclaris propria and invaded the mucosa and was exposed on its surface. Histopathologically, the tumor consisted of round and polygonal cells with clear-toeosinophilic granular cytoplasm. The tumor cells proliferated in a honeycomb-like appearance (Figure 2). The tumor cell nuclei showed hyperchromasia, nuclear enlargement, and prominent nucleoli. The tumor cells were negative for Fontana-Masson staining. Periodic acid-Schiff stain-positive intracytoplasmic granules, which were digested by diastage, were noted. The tumor cell showed slight to moderate nuclear atypia, with no mitosis or tumor necrosis. There was no lymphatic or vascular invasion.

Immunohistochemically, the tumor cells were positive for melanoma-associated antigen (HMB-45), neuronspecific enolase, CD68, and transcription factor E3
(TFE-3), but negative for AE1/AE3, CAM5.2, epithelial membrane antigen, smooth muscle actin, Desmin, MyoD1, Caldesmon, Calponin, Synaptophysin, Chromogranin A, NCAM, Vimetin, CD34, S-100, Melan-A, CD99, CD10, D2-40, CD138, P-ALP, and multiple myeloma oncogene-1 (Figure 3ab). The proliferation marker Ki-67 showed a nuclear positivity in approximately $15 \%$ of cells. An intestinal PEComa was diagnosis on the basis of these findings. This patient received only surgical resection. She is undergoing regular surveillance and remains free of disease at 15 months after operation.

\section{Discussion}

PEComas are part of a group of very rare mesenchymal neoplasms. Bonetti and colleagues [23] were the first to propose the concept of the perivascular epithelioid cell

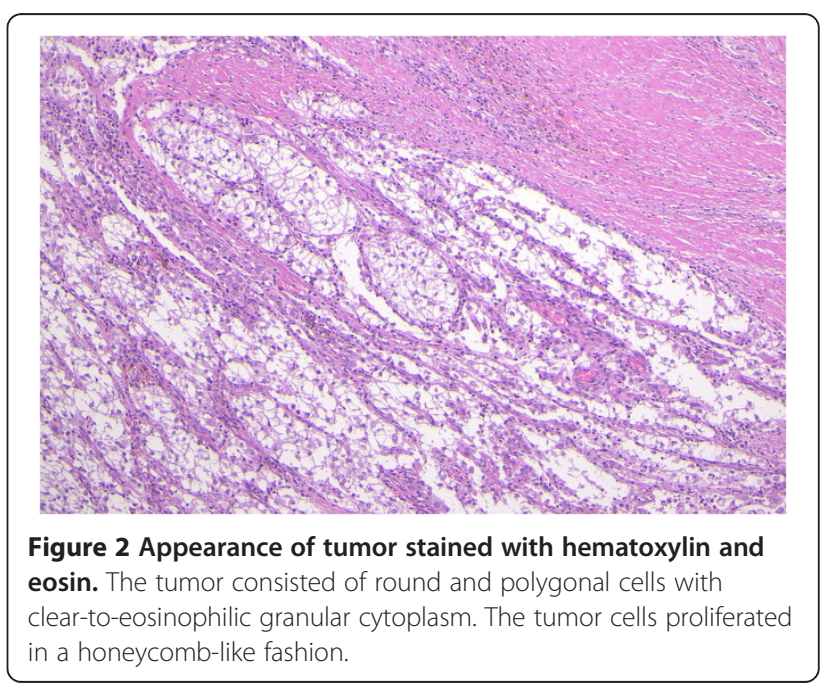




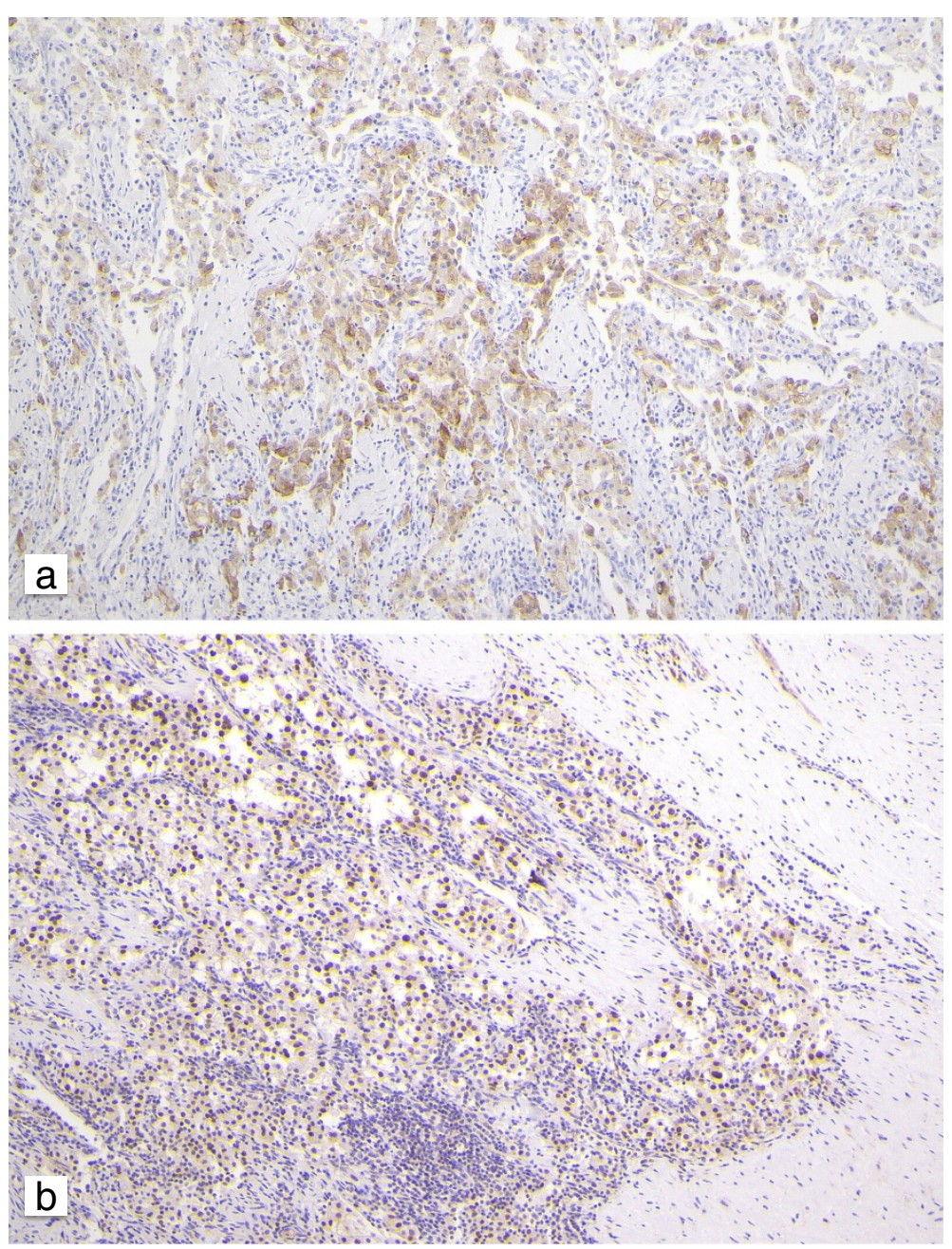

Figure 3 Immunohistochemical findings of the tumor. (a) HMB-45 is positive in the cytoplasm of the tumor cells. (b) Nuclear expression of TFE3 is observed in the tumor cells. HMB-45, melanoma-associated antigen; TFE3, transcription factor E3.

in 1992. The term PEComa was coined by Zamboni and colleagues [24] in 1996 to describe this rare family of lesions. In 2002, the World Health Organization accepted the designation PEComa as a distinct mesenchymal neoplasm consisting of histologically and immunohistochemically unique perivascular epithelioid cells [1]. This rare tumor has been reported in various organs, such as the falciform ligament, uterus, uterine cervix, liver, kidney, lung, breast, cardiac septum, pancreas, prostate, thigh, and gastrointestinal tract. PEComas usually show immunoreactivity for both melanocytic (HMB-45 and/or melan-A) and smooth muscle (actin and/or desmin) markers. Recently, several reports described TFE3 expression in PEComas $[14,22,25]$. In one review, TFE3 was positive for 3 of 24 cases of gastrointestinal PEComa. In our case, positivity for TFE3 contributed to the diagnosis of PEComa.

In this study, we focused on gastrointestinal PEComaNOS and did not include classic AML and LAM of the gastrointestinal tract in our review. The clinicopathological features of the PEComa-NOS included in this study are summarized in Table 1 . The ratio of males to women was 8 to 16 , suggesting that primary gastrointestinal PEComa-NOS is more common in females, similar to PEComa-NOS arising in other organs. Mean age at the diagnosis of primary gastrointestinal PEComa-NOS was 31.5 years (range 7 to 63 years). The mean diameter of primary gastrointestinal PEComa-NOS was $45.5 \mathrm{~mm}$ (range 12 to $100 \mathrm{~mm}$ ). The tumor was located in the colon in 14 patients $(58.3 \%)$, rectum in 5 (20.8\%), the small bowel in $2(8.3 \%)$, the duodenum in $2(8.3 \%)$, and the stomach in 1 (4.3\%). Surgical resection was performed in nearly all patients, and only two received adjuvant chemotherapy. One patient was given adjuvant interferon- $\alpha 2 b$ therapy, and the other case received adjuvant chemotherapy with doxorubicin, ifosfamide, and mesna in accordance with the Children's Oncology 
Table 1 Patient characteristics and tumor morphologic and histopathological features and outcomes

\begin{tabular}{|c|c|c|c|c|c|c|c|c|c|c|c|c|}
\hline Year & Author [reference] & $\begin{array}{c}\text { Age } \\
\text { (years) }\end{array}$ & Sex & Location & Size $(\mathrm{mm})$ & $\begin{array}{l}\text { Infiltrative } \\
\text { border }\end{array}$ & $\begin{array}{l}\text { Mitosis } \\
\text { (/50 HPF) }\end{array}$ & LVI & $\begin{array}{l}\text { Tumor } \\
\text { necrosis }\end{array}$ & Treatment & $\mathrm{AC}$ & Follow-up \\
\hline 2001 & Tazelaar et al., [4] & 9 & $\mathrm{~F}$ & Rectum & 30 & - & Rare & - & - & Trans anal resection & - & NER at 14 months \\
\hline 2001 & Tazelaar et al., [4] & 40 & $\mathrm{~F}$ & Rectum & 80 & - & Rare & - & - & Excision & - & NER at 6 months \\
\hline 2003 & Yanai et al., [5] & 32 & $\mathrm{~F}$ & Jejunum & 75 & - & n.a & - & + & Partial resection of jejunum & - & $\begin{array}{l}\text { Pelvic wall recurrence at } 13 \text { months, Right } \\
\text { ovary recurrence at } 25 \text { months }\end{array}$ \\
\hline 2004 & Birkahaeuser et al., [6] & 35 & $\mathrm{~F}$ & Cecum & 35 & n.a & Few & n.a & - & Right hemicolectomy & - & n.a \\
\hline 2004 & Genevay et al., [7] & 38 & $\mathrm{~F}$ & Cecum & 35 & n.a & Rare & n.a & - & Right hemicolectomy & n.a & n.a \\
\hline 2005 & Evert et al., [8] & 58 & $\mathrm{~F}$ & Rectum & 80 & n.a & 286 & n.a & + & n.a & n.a & n.a \\
\hline 2005 & Yamamoto et al., [9] & 43 & $\mathrm{~F}$ & Descending & 80 & n.a & 2 & + & + & Partial colectomy & - & $\begin{array}{l}\text { Peritoneal dissemination at } 20 \text { months, DOD } \\
\text { at } 38 \text { months }\end{array}$ \\
\hline 2005 & Mhanna et al., [10] & 15 & M & Duodenum & 45 & + & Low & n.a & - & Pancreaticoduodenectomy & - & NER at 24 months \\
\hline 2006 & Baek et al., [11] & 16 & $\mathrm{~F}$ & Transverse & 25 & n.a & 0 & n.a & - & Endoscopic resection & - & NER at 24 months \\
\hline 2006 & Agimy et al., [12] & 63 & $\mathrm{~F}$ & lleum & 45 & n.a & 13 & n.a & + & Partial resection of ileum & - & Abdominopelvic recurrence at 14 months \\
\hline 2008 & Narayanaswamy et al., [13] & 34 & M & Duodenum & 35 & + & n.a & - & - & Duodenectomy & - & NER at 18 months \\
\hline 2008 & Cho et al., [14] & 16 & $\mathrm{~F}$ & Transverse & 18 & n.a & n.a & - & - & n.a & - & NER at 41 months \\
\hline 2008 & Pisharody et al., [15] & 11 & M & Sigmoid & 12 & n.a & Rare & n.a & n.a & Partial colectomy & - & NER at 5 months \\
\hline 2008 & Righi et al., [22] & 11 & M & Sigmoid & 35 & + & Rare & n.a & + & Segmental resection & - & n.a \\
\hline 2009 & Ryan et al., [16] & 15 & $\mathrm{~F}$ & Rectum & 37 & - & 2 & - & + & Low anterior resection & + & NER at 9 months \\
\hline 2009 & Qu et al., [17] & 43 & $\mathrm{~F}$ & Cecum & 20 & - & 3 & - & - & Right hemicolectomy & - & NER at 25 months \\
\hline 2010 & Park et al., [18] & 7 & M & Ascending & 37 & n.a & n.a & n.a & n.a & Right hemicolectomy & + & NER at 26 months \\
\hline 2010 & Shi et al., [19] & 38 & $\mathrm{~F}$ & Sigmoid & 60 & n.a & n.a & n.a & - & Segmental resection & - & NER at 8 months \\
\hline 2010 & Shi et al., [19] & 42 & M & Ascending & 45 & n.a & n.a & n.a & - & Segmental resection & - & NER at 15 months \\
\hline 2010 & Shi et al., [19] & 38 & $\mathrm{~F}$ & Descending & 48 & n.a & n.a & n.a & - & Segmental resection & - & NER at 32 months \\
\hline 2010 & Shi et al., [19] & 45 & M & Ascending & 35 & n.a & n.a & n.a & - & Segmental resection & - & NER at 36 months \\
\hline 2010 & Freeman et al., [21] & 17 & $\mathrm{~F}$ & Sigmoid & 60 & - & Low & n.a & n.a & Partial resection & - & NER at 15 months \\
\hline 2012 & Waters et al., [20] & 42 & M & Gastric & 100 & n.a & n.a & n.a & n.a & Distal gastrectomy & - & DOD at 3 months \\
\hline 2012 & Present case & 55 & $\mathrm{~F}$ & Rectum & 25 & + & 0 & - & - & Trans anal resection & - & NER at 12 months \\
\hline
\end{tabular}

150 HPF 50 high-power fields, $A C$ adjuvant chemotherapy, DOD died of disease, $F$ female, $L V I$ lymphovascular invasion, $M$ male, n.a no data available, NER no evidence of recurrence. 
Group non-rhabdomyosarcoma soft tissue sarcoma protocol. Neither of these patients had any evidence of recurrence. Follow-up data were available for 19 patients, and the median follow-up was 15 months (range 3 to 41 months) after surgery. Three cases had recurrence $[5,12]$, two of whom underwent re-resection of their tumors. The 3-year disease free survival rates of the 19 patients was $75 \%$. Two patients died of their disease. One patient died 3 months after surgery, and the other died 38 months after the first operation.

Although the treatment of choice for gastrointestinal PEComa is surgical resection, the overall management strategy for gastrointestinal PEComa remains to be established. Furthermore, potential benefits of adjuvant chemotherapy have not been investigated. In a recent study of PEComa of soft tissue and gynecologic origin, Folpe and colleagues [25] suggested criteria for classifying PEComas into benign, uncertain malignant potential, and malignant categories. They proposed that malignancy was predicted by the presence of two of the following findings: tumor size greater than $5 \mathrm{~cm}$, infiltrative tumor border, high nuclear grade and cellularity, more than 1 mitosis/50 high-power fields, tumor necrosis, and vascular invasion. In our patient, the tumor was classified as low grade according to these diagnostic criteria because there was an infiltrative tumor border, but none of the other findings.

Given the present situation, close follow-up, including imaging studies and colonoscopy, is mandatory after surgical resection of gastrointestinal PEComa, especially in patients with high-grade malignancy. Because the outcomes of gastrointestinal PEComa remain unclear, further long-term studies in larger number of patients are needed.

\section{Conclusions}

We reported a rare case of rectal PEComa and reviewed the clinicopathological characteristics of gastrointestinal PEComa-NOS. At the present time, the most effective treatment for gastrointestinal PEComa is surgical resection. But the postoperative management including adjuvant chemotherapy still has not been established. So patients with postoperative PEComa-NOS should be carefully followed up.

\section{Consent}

Written informed consent was obtained from the patient for publication of this case report and accompanying images. A copy of the written consent is available for review by the Editor-in-Chief of this journal.

\section{Abbreviations}

AML: Angiomyolipoma; CCST: Clear-cell "sugar" tumors; HMB-45: Melanomaassociated antigen; LAM: Lymphangioleiomyomatosis; PEComa: Perivascular epithelioid cell tumor; PEComa-NOS: PEComa-not otherwise specified; TFE3: Transcription factor E3.

Competing interests

The authors declare that they have no competing interests.

\section{Authors' contributions}

AK, SF, TG, Al, TO, and TF performed the surgical treatment. AK and SF drafted the manuscript. TI and AN performed the pathological studies. NY, YR, TI and MM revised this manuscript. CK critically reviewed the manuscript and gave final approval for publication. All authors have read and approval the final manuscript.

\section{Author details}

${ }^{1}$ Gastroenterological Center, Yokohama City University Medical Center, 4-57 Urafune-cho Minami-ku, Yokohama-shi, Kanagawa-ken 232-0024, Japan. ${ }^{2}$ Department of Surgery, Yokohama City University, 3-9 Fukuura, Kanazawa-ku, Yokohama-shi, Kanagawa-ken 236-0004, Japan. ${ }^{3}$ Department of Pathology, Yokohama City University Medical Center, 4-57 Urafune-cho Minami-ku, Yokohama-shi, Kanagawa-ken 232-0024, Japan.

Received: 14 June 2013 Accepted: 25 December 2013

Published: 13 January 2014

\section{References}

1. Folpe AL: Neoplasms with perivascular epithelioid cell differentiation (PEComas). In World Health Organization Classification of Tumors: Pathology and Gentetics of Tumors of Soft Tissue and Bone. Lyon: IARC Press; 2002

2. Armah HB, Parwani AV: Malignant perivascular epithelioid cell tumor (PEComa) of the uterus with late renal and pulmonary metastases: a case report with review of the literature. Diagn Pathol 2007, 2:45.

3. Fadare O, Parkash V, Yilmaz Y, Mariappan MR, Ma L, Hileeto D, Qumsiyeh $M B$, Hui P: Perivascular epithelioid cell tumor (PEComa) of the uterine cervix associated with intraabdominal "PEComatosis": a clinicopathological study with comparative genomic hybridization analysis. World J Surg Oncol 2004, 2:35.

4. Tazelaar HD, Batts KP, Srigley JR: Primary extrapulmonary sugar tumor (PEST): a report of four cases. Mod Pathol 2001, 14:615-622.

5. Yanai $\mathrm{H}$, Matsuura $\mathrm{H}$, Sonobe $\mathrm{H}$, Shiozaki S, Kawabata K: Perivascular epithelioid cell tumor of the jejunum. Pathol Res Pract 2003, 199:47-50

6. Birkhaeuser F, Ackermann C, Flueckiger T, Guenin MO, Kern B, Tondelli P, Peterli R: First description of a PEComa (perivascular epithelioid cell tumor) of the colon: report of a case and review of the literature. Dis Colon Rectum 2004, 47:1734-1737.

7. Genevay M, McKee T, Zimmer G, Cathomas G, Guillou L: Digestive PEComas: a solution when the diagnosis fails to "fit". Ann Diagn Pathol 2004, 8:367-372

8. Evert M, Wardelmann E, Nestler G, Schulz HU, Roessner A, Röcken C: Abdominopelvic perivascular epithelioid cell sarcoma (malignant PEComa) mimicking gastrointestinal stromal tumour of the rectum. Histopathology 2005, 46:115-117.

9. Yamamoto H, Oda Y, Yao T, Oiwa T, Kobayashi C, Tamiya S, Kawaguchi K, Hino O, Tsuneyoshi M: Malignant perivascular epithelioid cell tumor of the colon: report of a case with molecular analysis. Pathol Int 2006, 56:46-50.

10. Mhanna T, Ranchere-Vince D, Hervieu V, Tardieu D, Scoazec JY, Partensky C: Clear cell myomelanocytic tumor (PEComa) of the duodenum in a child with a history of neuroblastoma. Arch Pathol Lab Med 2005, 129:1484-1486.

11. Baek JH, Chung MG, Jung DH, Oh JH: Perivascular epithelioid cell tumor (PEComa) in the transverse colon of an adolescent: a case report. Tumori 2007, 93:106-108.

12. Agaimy A, Wunsch PH: Perivascular epithelioid cell sarcoma (malignant PEComa) of the ileum. Pathol Res Pract 2006, 202:37-41.

13. Srikanth Narayanaswamy, Nanda Venkatanarasimha, Buckley D, Puckett M: Duodenal PEComa: a review of literature. Eur J Radiol Extra 2008, 67:e121-e123.

14. Cho HY, Chung DH, Khurana H, Zhai QJ, Ro JY: The role of TFE3 in PEComa. Histopathology 2008, 53:236-249. 
15. Pisharody U, Craver RD, Brown RF, Gardner R, Schmidt-Sommerfeld E: Metastatic perivascular epithelioid cell tumor of the colon in a child. J Pediatr Gastroenterol Nutr 2008, 46:598-601.

16. Ryan P, Nguyen VH, Gholoum S, Carpineta L, Abish S, Ahmed NN, Laberge JM, Riddell RH: Polypoid PEComa in the rectum of a 15-year-old girl: case report and review of PEComa in the gastrointestinal tract. Am J Surg Pathol 2009, 33:475-482.

17. Qu GM, Hu JC, Cai L, Lang ZQ: Perivascular epithelioid cell tumor of the cecum: a case report and review of literatures. Chin Med J (Engl) 2009, 122:1713-1715.

18. Park SJ, Han DK, Baek HJ, Chung SY, Nam JH, Kook H, Hwang TJ: Perivascular epithelioid cell tumor (PEComa) of the ascending colon: the implication of IFN-alpha2b treatment. Korean J Pediatr 2010, 53:975-978.

19. Shi HY, Wei LX, Sun L, Guo AT: Clinicopathologic analysis of 4 perivascular epithelioid cell tumors (PEComas) of the gastrointestinal tract. Int J Surg Pathol 2010, 18:243-247.

20. Waters PS, Mitchell DP, Murphy R, Mckenna M, Waldron RP: Primary malignant gastric PEComa - diagnostic and technical dilemmas. Int J Surg Case Rep 2012, 3:89-91.

21. Freeman HJ, Webber DL: Perivascular epithelioid cell neoplasm of the colon. World J Gastrointest Oncol 2010, 2:205-208.

22. Righi A, Dimosthenous K, Rosai J: PEComa: another member of the MiT tumor family? Int J Surg Pathol 2008, 16:16-20.

23. Bonetti F, Pea M, Martignoni G, Zamboi G: PEC and sugar. Am J Surg Pathol 1992, 16:307-308.

24. Zamboni G, Pea M, Martignoni G, Zancanaro C, Faccioli G, Gilioli E, Pederzoli $P$, Bonetti F: Clear cell "sugar" tumor of the pancreas. A novel member of the family of lesions characterized by the presence of perivascular epithelioid cells. Am J Surg Pathol 1996, 20:722-730.

25. Folpe AL, Mentzel T, Lehr HA, Fisher C, Balzer BL, Weiss SW: Perivascular epithelioid cell neoplasms of soft tissue and gynecologic origin: a clinicopathologic study of 26 cases and review of the literature. Am J Surg Pathol 2005, 29:1558-1575.

doi:10.1186/1477-7819-12-12

Cite this article as: Kanazawa et al:: Perivascular epithelioid cell tumor of the rectum: report of a case and review of the literature. World Journal of Surgical Oncology 2014 12:12.

\section{Submit your next manuscript to BioMed Central and take full advantage of:}

- Convenient online submission

- Thorough peer review

- No space constraints or color figure charges

- Immediate publication on acceptance

- Inclusion in PubMed, CAS, Scopus and Google Scholar

- Research which is freely available for redistribution 